\title{
Right aortic arch and Kommerell's diverticulum
}

\author{
PHILIP HC WONG, JWT LEE \\ From the Departments of Medicine and Surgery, University of Hong Kong, Queen Mary Hospital, Hong \\ Kong
}

Right aortic arch anomalies seldom produce symptoms in adult life. This report describes a patient with a right aortic arch, an aberrant left subclavian artery, and a large Kommerell's diverticulum, which caused oesophageal compression in her third decade. We discuss the surgical approach to this uncommon anomaly.

\section{Case report}

A 23-year-old woman was in good health until one year before admission, when she began to notice a sensation of obstruction behind the manubrium after having solid food and occasional choking after drinking. By the time of admission she had lost $10 \mathrm{~kg}$. There were no respiratory symptoms. Examination did not show any abnormal physical signs and the blood pressure was the same in both arms. Routine haematological and biochemical investigations gave normal results, and the electrocardiogram was also normal. A chest radiograph was normal except for a right

Address for reprint requests: Dr Philip Wong, Department of Medicine, University of Hong Kong, Queen Mary Hospital, Hong Kong.

Accepted 19 November 1982

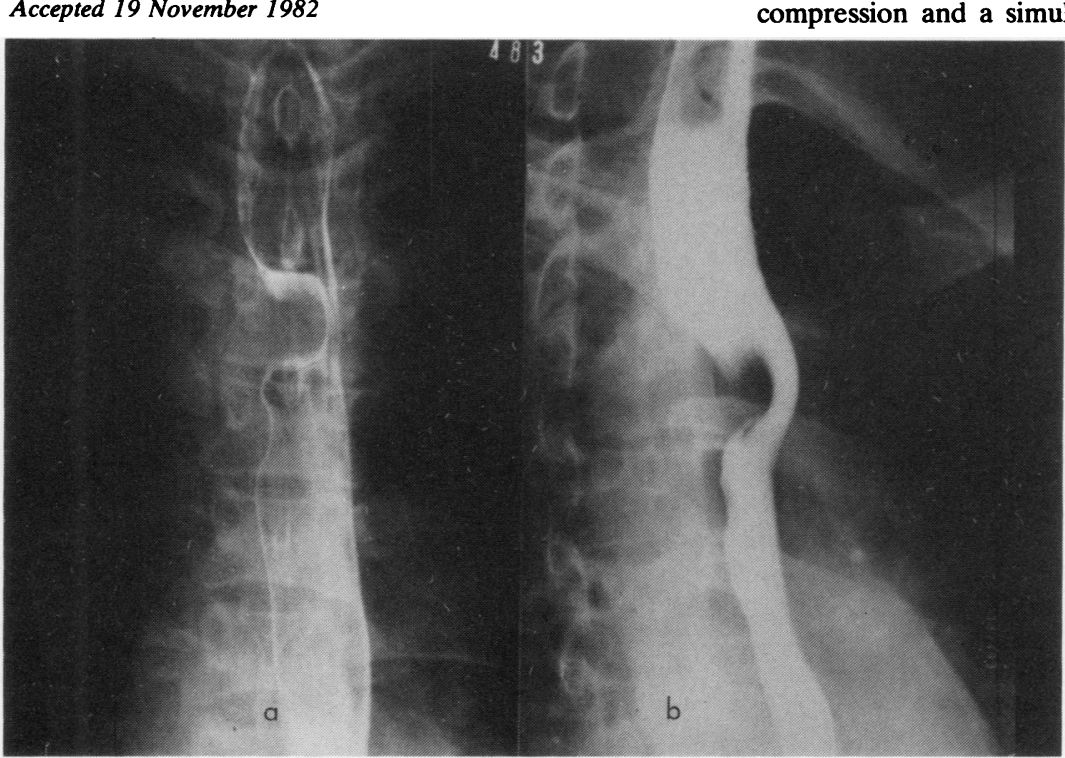

Fig 1 Barium swallow (a) in the anteroposterior and $(b)$ in the right anterior oblique projection, showing oesophageal compression on the right lateral and posterior aspect. aortic arch and descending aorta. A barium swallow confirmed oesophageal compression on the right lateral and posterior aspect (fig 1). Aortography showed a rightsided aortic arch and descending aorta, with an aberrant left subclavian artery, arising from a large Kommerell's diverticulum (fig 2).

Through a left posterolateral thoracotomy the left subclavian artery was identified in the posterior mediastinum to the right of the vertebral column, behind the oesophagus. No ligamentum arteriosum was identified. It was not possible to resect the Kommerell's diverticulum from this approach. The subclavian artery was freed from its attachment to the Kommerell's diverticulum and up to the apex of the left hemithorax. It was transected and transfixed at both ends. The part behind the oesophagus was further dissected and pushed to the right of the posterior mediastinum, as far away from the oesophagus as possible.

Immediately after operation the patient noticed improvement in her symptoms and she gained $7 \mathrm{~kg}$ in weight over the first six months, although a barium swallow still showed oesophageal compression. Symptoms of dysphagia began to return, however, and at one year her symptoms and body weight were the same as before the operation. A barium swallow again showed oesophageal compression and a simultaneous aortogram (fig 3) indi- 


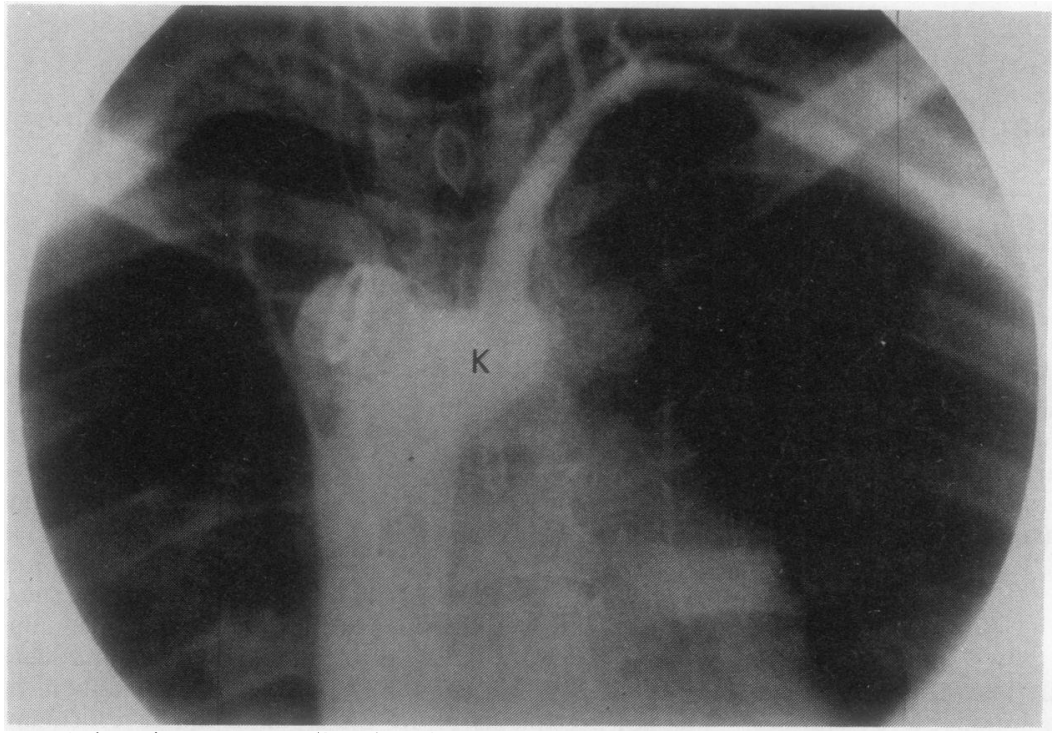

Fig 2 Descending aortogram showing the right-sided descending aorta and aberrant left subclavian artery arising from a large Kommerell's diverticulum $(K)$.

cated that the Kommerell's diverticulum was causing the obstruction. Through a right posterolateral thoracotomy a $2 \mathrm{~cm} \times 4 \mathrm{~cm}$ diverticulum was found behind the oesophagus, causing severe compression. This was resected and the patient noticed complete relief afterwards. Repeated barium studies showed no residual oesophageal compression.

\section{Discussion}

Since Gross reported the first surgical correction of a double aortic arch in $1945,{ }^{1}$ many varieties of vascular rings have been successfully operated on. The favoured approach is through a left thoracotomy, because of its sound anatomical and pathological basis. Indeed, this was the only approach used in several large series of surgical correction of vascular rings, and the successful results have confirmed its efficacy. ${ }^{2-7}$ There are, however, occasional anomalies in which right thoracotomy is more appropriate, as in our patient with oesophageal compression caused by a large Kommerell's diverticulum from a right-sided descending aorta. This diverticulum was first described in $1936^{8}$ but seldom causes oesophageal compression, and there is no mention of this anomaly in several large series of vascular rings. ${ }^{2-7}$

Shannon in 1961 was the first to describe such a case of oesophageal obstruction by a Kommerell's diverticulum from a left-sided aortic arch and descending aorta. ${ }^{9} \mathrm{We}$ could find only two cases in the published reports, in patients aged 8 months and 11 years old, ${ }^{10}$ that were

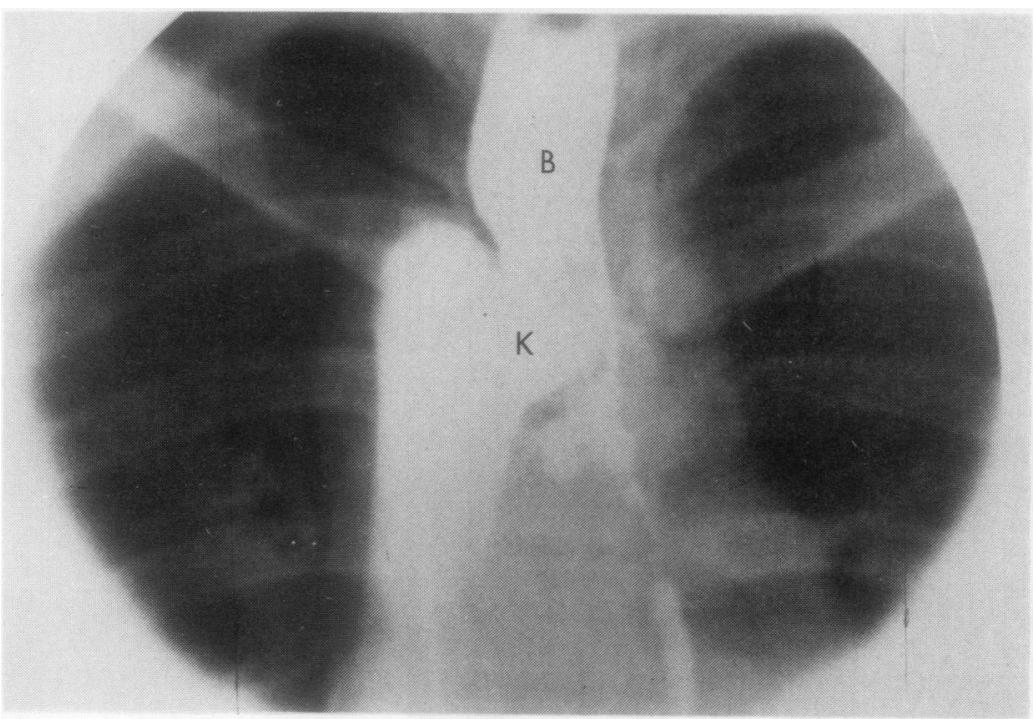

Fig 3 Simultaneous barium swallow $(B)$ and descending aortogram. 
exactly similar to ours. The authors emphasised that in this type of case excision of the diverticulum is mandatory and that a right thoracotomy should be chosen. Indeed, excision of the diverticulum was not possible through the left thoracotomy in our patient. Although temporary relief was obtained by dividing the left subclavian artery and freeing the fibrous bands and sheaths around the oesophagus, symptoms eventually returned and required a right thoracotomy for resection of the diverticulum. We believe that a right-sided approach should be chosen in such a case.

\section{References}

${ }^{1}$ Gross RE. Surgical relief for tracheal obstruction from vascular ring. N Engl J Med 1945;233:586-90.

${ }^{2}$ Nikaidoh H, Riker WL, Farouk SI. Surgical management of vascular rings. Arch Surg 1972;105:327-33.

${ }^{3}$ Wychulis AR, Kincaid OW, Weidman WH, Danielson GK. Congenital vascular rings: surgical considerations and results of operation. Mayo Clin Proc 1971;46:182-8.

4 Archiniegas E, Hakimi M, Hertzler JH, Farooki ZQ, Green EW. Surgical management of congenital vascular rings. $J$ Thorac Cardiovasc Surg 1979;77:721-7.

${ }^{5}$ Lincoln JCR, Deverall DB, Stark J, Aberdeen E, Waterston DJ. Vascular anomalies compressing the oesophagus and trachea. Thorax 1969;24:295-306.

- Binet JP, Langlois J. Aortic arch anomalies in children and infants. J Thorac Cardiovasc Surg 1977;73:248-52.

${ }^{7}$ Gross RE, Neuhauser EBD. Compression of the trachea or oesophagus by vascular anomalies. Surgical therapy in $\mathbf{4 0}$ cases. Paediatrics 1951;7:69-83.

- Kommerell B. Verlagerung des Ösophagus durch eine abnorm verlaufende Arteria subclavia dextra (arteria lusoria). Fortschritte omf dem Gebiete der Roentgenstrahlen und der Nuklearmedizin (Stuttgart) 1936;54:590.

9 Shannon JM. Aberrent right subclavian artery with Kommerell's diverticulum. J Thorac Cardiovasc Surg 1961;41:408-11.

10 Jung JY, Almond CH, Saab SB, Lababidi Z. Surgical repair of right aortic arch with aberrant left subclavian artery and left ligamentum arteriosum. $J$ Thorac Cardiovasc Surg 1978;75:237-43. 